\title{
“Charity begins at home": Informal caring barriers to formal volunteering among older people
}

\begin{abstract}
Formal volunteering is an important economic and social activity. In many countries, prevalence of volunteering is decreasing overall, including among older people who constitute a major volunteering resource. This qualitative study explored reasons for nonvolunteering among seniors, with a focus on those who attribute their non-volunteering to their existing helping commitments. Forty-nine Australian interviewees aged 60+ years described a range of social, psychological, and temporal factors that resulted in their prioritization of informal rather than formal volunteering activities. These factors are mapped onto a theoretical framework matrix, with social identity and social capital theories appearing to possess the most explanatory power. The findings suggest that programs designed to encourage formal volunteering among older people need to be implemented in a manner that recognizes that members of this group can hold many other responsibilities that limit their ability to participate, especially those assisting in the care of multiple generations.
\end{abstract}

Key words: Formal volunteering, Informal volunteering, Caregiving, Qualitative analysis 


\section{Introduction}

Societies and economies rely on the contributions of individuals to survive and thrive. The ways in which adults contribute to society through their labors are classified into four broad categories: paid employment, formal volunteering, informal volunteering, and informal caring (Hank and Stuck, 2008). Although there are numerous definitions, formal volunteering is generally differentiated from informal volunteering by whether or not individuals provide their unpaid services to others via an official affiliation with an organization (Carson, 1999; Cnaan and Amrofell, 1994). By comparison, informal caring involves providing unpaid assistance to those residing within the same household (Lee and Brudney, 2012).

Rapid population aging in many countries is resulting in larger proportions of the population being retired and therefore no longer contributing via paid positions in the workforce (Beard and Bloom, 2015). As a consequence, there is growing emphasis on encouraging older people to contribute via unpaid roles, especially formal volunteering, to minimize the impact of population aging on national productivity (Gonzales, Matz-Costa, and Morrow-Howell, 2015). In addition to contributing more than $\$ 400$ billion each year to the world economy (International Labour Office, 2011), volunteering has the potential to confer physical and psychological benefits to individuals. Previous research has identified associations between volunteering and positive physical outcomes including higher self-rated health ( $\mathrm{Li}$ et al,. 2013); greater functionality (Kail and Carr, 2017; Lum and Lightfoot, 2005), lower prevalence of hypertension (Burr et al., 2015), less time in hospital (Kim and Konrath, 2016, Lum and Lightfoot, 2005; Tomoika et al., 2017), higher cognitive functioning (Gupta, 2018; Proulx et al., 2018), and reduced mortality (Li et al., 2013). Positive psychological outcomes have been found to include higher levels of life satisfaction and subjective well-being (Binder 
and Freytag, 2013; Ho, 2017; Kahana et al., 2013; Li et al., 2013), greater social connectedness (Brown et al., 2012; Connolly and O'Shea, 2015; Creaven, Healy, and Siobhan, 2017), and lower rates of depression (Li and Ferraro, 2005; Lum and Lightfoot, 2005).

Despite societal and individual benefits, volunteering rates in countries such as the United Kingdom, the United States, and Australia have experienced a recent decline (Australian Bureau of Statistics, 2011a, 2015, 2017b; UK Cabinet Office, 2015; US Bureau of Labor Statistics, 2016). Available data indicate that these population-level decreases are also occurring specifically among older people (Australian Bureau of Statistics, 2011a, 2015; US Bureau of Labor Statistics, 2016). There is therefore a need to better understand the forces at play behind individuals' volunteering decisions to inform policies and programs designed to promote participation among retirees. One potential explanation for this trend is an increase in informal volunteering relative to formal volunteering (Australian Bureau of Statistics, 2017b), but this is difficult to ascertain because most research in this area focuses on formal volunteering, and other forms of unpaid labor are not well documented (Petriwskyj and Warburton, 2007b; Wang, Mook, and Handy, 2016).

\section{The decision to volunteer}

Functional accounts of volunteering behavior focus on the needs of volunteers that can be fulfilled by engaging in volunteering activities (Bales, 1996; Clary and Snyder, 1999; Clary et al. 1998). Needs of relevance to older volunteers include expressing humanitarianism, strengthening social relationships, maintaining or developing skills, and personal growth. To some extent, it is likely that these needs can be fulfilled by undertaking either formal or informal caring roles, and it is expected that similar motivations underlie these different 
methods of contributing to the welfare of others (Finkelstein and Brannick, 2007; Taniguchi, 2011). However, there are likely to be numerous factors that influence whether individuals choose one form of unpaid labor over another (Warburton, 2015; Wilson and Musick, 1997). Caring duties are typically considered more obligatory than formal volunteering activities (Hank and Stuck, 2008), and can be especially physically and mentally taxing (Morgan et al., 2016). There tend to be greater societal expectations that women will perform caring roles (Horrell et al., 2015), potentially meaning that women are more likely to experience any negative effects of caring and are less likely to obtain the positive benefits of formal volunteering due to their caring commitments.

The factors influencing the types of volunteering and caring activities undertaken have yet to be adequately explored, and it is expected that individuals' life circumstances will act as motivators or inhibitors to their participation in different kinds of volunteering behaviors (Gray et al., 2012). There have been repeated and ongoing calls for further research to investigate (i) the extent to which various other caring activities may impede individuals' capacity and willingness to engage in formal volunteering and (ii) the relevant motivations that influence individuals' choices between these forms of activity (Dury et al., 2016; GilLacruz, Marcuello, and Saz-Gil, 2017; Hank and Stuck, 2008; Lee and Brudney, 2009; Nancy Morrow-Howell, 2010; van der Horst et al., 2016; Wang et al., 2016; Wilson and Musick, 1997).

Among the studies to date that have specifically attempted to determine whether engaging in informal volunteering and/or caring duties competes with or complements formal volunteering among older people, no clear pattern has emerged. While most studies appear to demonstrate that there is complementarity between the two forms of activity as indicated by 
the tendency for individuals to participate in both (e.g., Bulanda and Jendrek, 2016; Gray, Khoo, and Reimondos, 2012; Hank and Stuck, 2008; Lee and Brudney, 2012; Plagnol and Huppert, 2009; Taniguchi, 2011), some suggest competition exists between the activities (e.g., Dury et al., 2016), and others fail to find support for either complementarity or competition (e.g., van der Horst et al., 2016).

Evident in many prior studies is an apparent assumption that formal volunteering constitutes the 'gold standard' of seniors' contributions to society, and that participation in this 'higher level' contribution may be positively or negatively affected by other activities. There is some recognition, however, that contributions in the form of informal volunteering and caring have value and are important to facilitate the functioning of family units, which in turn have productive value for the economy as a whole (Kelemen, Mangan, and Moffat, 2017; Martinez et al., 2011). For example, looking after the dying in their own homes is a key attribute of “compassionate communities" (Horsfall et al., 2012), and can provide both patient and carer with a sense of social integration and belonging (Horsfall et al., 2017).

Given (i) the substantial individual and societal benefits derived from volunteering and caring activities, (ii) the opportunities presented by population aging to access growing numbers of potential volunteers, and (iii) declining rates of formal volunteering, it is important to better understand the choices older people make between different forms of unpaid labor. This information can be useful in multiple ways. In the first instance, it could prevent undue pressure being placed on those who do not have the opportunity, inclination, or ability to participate in formal volunteering by illustrating the scale and nature of their other service commitments. Second, it could inform future interventions designed to assist individuals who wish to contribute in multiple ways to better manage the competing demands of different 
forms of volunteering and caring. Finally, a deeper understanding of the logistical requirements of different roles may provide insights into likely windows of opportunity to attract older people into formal volunteering roles once their other commitments have been completed or reduced in intensity. The aim of this study was therefore to explore the nature of barriers to formal volunteering among those who participate in informal volunteering or caring roles.

The context of this study is Australia, where $21 \%$ of the population is aged 60 years and older (Australian Bureau of Statistics, 2017a). Reflecting rapid population aging, there is no longer a mandatory retirement age and the eligibility threshold for the age pension is increasing progressively (scheduled to reach 67 years by 2023: Australian Government, 2009). Almost one-third $(31 \%)$ of Australians report engaging in formal volunteering, with decreasing participation by age within the older age group (Australian Bureau of Statistics, 2017b). The prevalence rate is $35 \%$ among $65-74$ year olds, $26 \%$ among $75-84$ year olds, and $19 \%$ among those aged 85 years and older (Australian Bureau of Statistics, 2017b).

\section{Method}

Most prior research investigating decision-making relating to volunteering has either involved population samples that include both volunteers and non-volunteers to identify any differences between the groups (Bulanda and Jendrek, 2016; Dury et al., 2016; Gil-Lacruz et al., 2017; Gray et al., 2012; Hank and Stuck, 2008; Lee and Brudney, 2009; Mitani, 2013; Plagnol and Huppert, 2009; Taniguchi, 2011; van der Horst et al., 2016; Wang et al., 2016; Warburton and Stirling, 2007; Yeung, 2016) or only included current volunteers (Hong and Morrow-Howell, 2013; Kelemen et al., 2017; Larkin, Sadler, and Mahler, 2005; Tang, Choi, 
and Morrow-Howell, 2010). The present study adopted an alternative approach by intentionally sampling those who do not engage in formal volunteering to identify factors contributing to their lack of participation. It has been suggested that qualitative approaches may be especially useful in identifying and explicating the trade-offs involved in individuals' volunteering decisions (Lee and Brudney, 2009). As such, an inductive, qualitative approach was used to allow relevant factors to emerge and to allow participants to express in their own words the ways in which different factors may interact to influence volunteering decisions.

As part of a larger study exploring the role of volunteering in healthy aging (blinded for review), Australians aged 60+ years who were not currently engaging in formal volunteering were recruited to participate in individual interviews. One aim of these interviews was to identify barriers to volunteering that may be addressed in future interventions designed to increase participation among retired Australians. Numerous participant recruitment methods were used, including notices in newspapers, flyers delivered to retirement villages, radio announcements, and information distributed at various seniors' events. Eligibility criteria included being at least 60 years of age, fully retired, adequately mobile to attend an oncampus interview, and not currently engaging in formal volunteering. The study received clearance from a University Human Research Ethics Committee.

The semi-structured interviews were conducted at two university campuses located within the Perth metropolitan area - one north and one south of the city. Participants could select the campus that was most convenient for them to attend. During the interview, a funnel approach was adopted (Gordon, 1969). This involved commencing with broad, open-ended questions to allow issues to be raised spontaneously (e.g., "What do you think of when you hear the word 'volunteering'?"), followed by more directed questioning later in the interview to 
follow up on specific points of interest (e.g., "Have you done any formal volunteering at all throughout your life?", "What are the barriers to people doing volunteering?"). The discussion points covered during the interviews of direct relevance to the present study included the individual's volunteering history, their attitudes to formal volunteering, and any factors preventing them from engaging in formal volunteering at the present time. Other discussion topics of relevance to the broader study related to perceptions of healthy aging and engagement in physical, mental, and social activities in later life and across the lifespan.

The interviews were audio-recorded and subsequently transcribed verbatim. The transcripts were imported into NVivo 11 (QSR International) for inductive coding and analysis (Glaser and Strauss, 1967). The transcripts were read in their entirety and the derived NVivo nodes (the locations in which data are stored according to their assigned codes) were interrogated to obtain a detailed understanding of specific issues that arose. Due to the emergent nature of the coding process, a single coder (the first author) undertook the coding process, which involved developing a coding hierarchy that was progressively expanded to account for the various themes evident in the data (Bradley, Curry, and Devers, 2007). This approach is appropriate for circumstances in which the analysis is not theory-driven and the aim is to develop new insights, hence preventing the use of a pre-specified coding framework from which to assess inter-coder reliability (Smith and McGannon, 2017). However, the first and second authors conducted the interviews and the second author reviewed the sections of the transcripts that related to volunteering. This enabled detailed discussions leading to the categorization of barriers associated with participants' informal volunteering and caring roles as outlined below. The trustworthiness of the interpretation was enhanced via discussions among the other members of the research team and a comparison of the findings with relevant theoretical constructs (Fram, 2013). 


\section{Results}

In total, 242 seniors were interviewed (sample profile shown in Table 1). Among those participants expressing a reluctance to engage in formal volunteering, the reasons provided were generally consistent with those previously reported in the literature. These reasons included health conditions, lack of time, low confidence, transport issues, and disinterest (Caro and Bass, 1997; Petriwskyj and Warburton, 2007a; Sundeen, Raskoff, and Garcia, 2007). Of specific relevance to the present study was the sub-sample of participants who discussed the assistance they already provide for those in need and the ways in which these commitments prevent them from being able to engage in formal volunteering. One in five participants $(n=49,20 \%)$ made reference to these other caring duties as meaningful contributions they make to the welfare of others and hence that could be considered to fulfil their social contribution obligations. The analysis to follow relates only to these participants. As shown in Table 1, study participants reporting participation in informal volunteering and caring roles in lieu of formal volunteering were more likely to be female, to have lower levels of education, and to be among the younger members of the larger sample. They were also less likely to be of higher socioeconomic status compared to the total sample.

\section{Insert Table 1 about here}

Of note is that in all instances the nominated informal volunteering and caring duties related to providing assistance to other people rather than performing roles relating to other kinds of recipients (e.g., animals or the environment). While more task-focused activities were sometimes discussed in other parts of the interviews (such as mentions of having volunteered 
at animal shelters in earlier life phases), people-focused activities that involved providing services for others within their social networks dominated explanations for avoiding or delaying formal volunteering at this stage of their lives.

Participants' explanations of the nature of their contributions suggest three primary categories of barriers to formal volunteering: social, psychological, and temporal factors. Each category is described below with illustrative quotes provided.

\section{Social responsibilities}

By far the most frequently discussed barrier to participating in formal volunteering among this sub-sample of interviewees was their prioritization of others within their immediate social networks. As noted above, according to existing conceptualizations of volunteering and caring, the assistance provided for members of these networks would be classified as either informal caring where they occur within the same residence or informal volunteering where they occur elsewhere. However, the study participants did not make this distinction, and instead there was a clear hierarchy of commitment according to the nature of the relationship held - family members were generally considered to be most entitled to greater levels of assistance, followed by friends and then neighbors. The unknown others who would be the recipients of their efforts if they engaged in formal volunteering were described as being much lower on the priority list. As such, although some had previously engaged in formal volunteering and intended to do so again, their current activities focused on attending to loved ones who were in need of their assistance at that point in time. As noted by one participant, "Charity begins at home" (F (female), 60-70 years). 
When discussing the needs of family members, the study participants nominated several different groups of individuals for whom they were caring on a regular basis. Grandchildren were mentioned most frequently, and there appeared to be an especially high degree of loyalty, connection, and attachment to this recipient group:

I have six grandchildren. Rightly or wrongly, if I'm going to do anything for anybody, they're my first port of call (F, 70-79 years).

My grandchildren are precious to me. One day they'll grow up and they'll say "Nana, now we need some space". I know that day will come, so then I will go and do volunteering ( $\mathrm{F}, 60-69$ years).

Relatedly, adult children were also often mentioned due to babysitting constituting a service provided for both adult children and grandchildren:

If my children had to pay me for the babysitting I do and I've done in the last five years to them alone, I'd be a millionaire. I'd be out floating around the world or somewhere (F, 70-79 years).

However, in some instances adult children were care recipients in their own right, especially where they were described as suffering from illness or incapacity:

We have a daughter actually who is disabled, so she needs quite a fair bit of attention. So I think the effort I think is more put on her rather than trying to take on too much (M (male), 60-69 years). 
We lost a son to drugs, and I have another son that's a drug addict, and he's 37.

So it takes up a lot of time (M, 70+ years).

Finally, ill spouses, elderly parents, and other relatives could also require high levels of care:

My wife had a fall and then the hip and all...so my family kind of comes first (M, 70-79 years).

I used to do volunteering. I think because I care for my mother, I now feel as though I'm doing quite a bit. And I'm caring for an uncle (F, 60-69 years).

When my mother was alive I was her carer, and my father of course, and my husband (F, 70-79 years).

Where friends and neighbors were nominated as requiring assistance, these two categories of care recipients were typically described in quite different ways. In the small number of instances where friends were described as the recipient group, it was more often in terms of end-of-life care that was highly intensive. For example, one interviewee who was a member of a migrant community described how she has assisted friends who are terminally ill because their inability to speak English means they need carers from within their community:

My friends who don't speak English - I have these people, I have a few that die one after another. I had one friend with cancer and I look after her for a while. Then two years later, she passed away. Then another one just happened and she 
passed away. So the last two years I have been pretty occupied with people who have had cancer (F, 60-69 years).

By comparison, neighbors were more likely to be reported as needing regular, small tasks performed to assist them age in place:

I help my neighbors all the time. I've got a block of units near me with very old people, you know, like the aged. So every now and then they call upon me to help them do things. My neighbor across the road is old as well, so I just call on them and make sure they're all right and if they need any help (F, 60-69 years).

The primacy of social factors was evident in the extent to which the psychological and temporal factors outlined below were typically discussed in relation to commitments to those within existing social networks. For example, psychological strain was expressed in terms of the intense experiences of caring for very ill loved ones and temporal factors related to juggling the time demands of multiple forms of assistance provided to important others.

\section{Psychological factors}

Some participants reported adverse psychological outcomes from their existing contributions that prevented them from taking on formal volunteering roles at that point in time. These barriers related to the stress experienced in their current or previous caring duties, a desire to avoid placing themselves in unpleasant or emotionally intense situations, and anxiety about letting people down. 
The highest levels of stress were apparent among those who had cared or were currently caring for dying loved ones. In some instances this could leave individuals feeling they had nothing left to give anyone else, even when their caring responsibilities had ended:

I've got no patience left for that (volunteering) unfortunately, because I've got too many dead people in my life. I've got two dead husbands and several dead friends, so I don't have the patience left. That's what I am, totally out of patience (F, 60-69 years).

Similarly, those currently involved in physically and emotionally draining caring roles expressed the need to avoid any other activities that could result in further negativity or hardship. Their existing duties were considered to be adequately taxing to absolve them of the need to undertake other forms of volunteering:

I haven't got enough patience to help out with elderly. I'm having enough trouble with my mother... at the moment my mum requires quite a bit of looking after $(\mathrm{F}$, 60-69 years).

Concerns about disappointing others typically related to the need to prioritize loved ones' needs, which was seen as being likely to result in short-notice cancellations if any other volunteering duties were undertaken. For some of the study participants, this generated feelings of anticipated regret that prevented them from being willing to make commitments to those outside their existing social networks: 
If you say yes, and then all of a sudden, I can't do that day, well you're actually letting those people down...it's not going to be nice for them because I've taken time out and they needed me (F, 60-69 years).

\section{Temporal factors}

The time commitments associated with providing care had three primary dimensions: the total time taken to attend to others, the specific times of the day/week when help was required, and the logistical difficulties associated with attempting to meet multiple and competing demands on their time. In terms of total time devoted to caring for those within their social networks, this was most apparent at both the beginning and end of life of the care recipients. Grandchildren who were too young to attend school were reported as consuming large amounts of time when grandparents took responsibility for their care during working hours:

My life is still very hectic because I'm bringing up the grandson ( $\mathrm{F}, 60-69$ years).

Providing palliative care was also described as all-consuming, and the period of care could be quite extended:

I've been looking after my husband for the last nine years...I haven't been able to volunteer because of my own personal stuff going on in my family - a dying husband and a grandson with leukemia (F, 70-79 years). 
In terms of specific timing, the nature of the assistance provided to others often meant there was no scheduling flexibility and it was necessary for the older person to arrange their affairs around the needs of those for whom they care. A common example was babysitting duties that required grandparents to be available at very specific times on specific days to accommodate their grandchildren's school hours and extra-curricular activities:

Three times a week I go and fetch them (grandchildren) from school. I take one to netball and take another to soccer, and hang around there until his dad comes and then I hand them over to him (F, 70-79 years).

A related issue was the tendency for certain forms of care to be irregular or sporadic, making it difficult to commit to any other responsibilities. This was most often the case among those providing ad hoc babysitting services for family members (sometimes referred to as being "on call") and those who were caring for the sick and responsible for ensuring their charges attended medical appointments:

With my babysitting and being on call and that, I don't volunteer (F, 70-79 years).

I'm looking after my husband - it's unpredictable when he's got doctor's appointments (F, 60-69 years).

\section{Discussion}

Independently or in combination, social, psychological, and temporal factors were identified by the study participants as substantial impediments to taking on formal volunteering roles. 
These factors were manifest in various forms of existing caring commitments that prevented participants from being willing or able to engage in formal volunteering. Overall there was a sense that these individuals belonged to a 'sandwich generation' that could have caring responsibilities covering four generations - grandchildren, children, and elderly relatives, along with spouses, friends, and neighbors of their own generation. This emphasis on caring was reflected in the fact that all informal and caring roles were described as people-focused rather than task-focused (as per Finkelstein and Brannick's (2007) categorization), and in the tendency for those reporting participation in informal roles in lieu of formal volunteering to be somewhat younger than the members of the larger non-volunteering sample and hence more likely to have both young grandchildren and elderly relatives with care needs.

Previous research has assigned sandwich generation status to middle-aged individuals (Grundy and Henretta, 2006), but increasing longevity and demographic shifts to fewer children per family are resulting in more 'vertical' familial networks comprised of a larger number of generations but with fewer members in each (Puur et al., 2011). This has potential implications for the number and range of caring roles commonly undertaken by today's seniors, and may go some way towards explaining observed declines in formal volunteering rates (Australian Bureau of Statistics, 2011a, 2015, 2017b). By meeting the diverse needs of those within their social networks, older people provide valuable services that would otherwise constitute economic costs for society (Martinez et al., 2011). Of note is that those of higher socioeconomic status in the larger sample were less likely to nominate these kinds of caring roles as reasons for not engaging in formal volunteering, which may be partly due to their increased ability (and that of their family members) to outsource at least some of these caring roles to external providers. 
It is recognized that there can be no single over-arching theory of volunteering because of the complexity of the phenomenon (Hustinx, Cnaan, and Handy, 2010), and instead numerous theoretical frameworks have been nominated in the literature as being potentially relevant to individuals' volunteering decisions. This complexity was apparent in the results of the present study, with each category of barriers demonstrating various dimensions that lend themselves to multiple theoretical interpretations. Table 2 provides a matrix of the theoretical frameworks that appear to be particularly useful in understanding each inductively derived category, with social identity and resource theories presenting as having the greatest utility across categories.

\section{Insert Table 2 about here}

Derived from social psychology, social identity theory delineates people into in-groups and out-groups, with the former viewed as extensions of the self to the extent that efforts to benefit members of the in-group are perceived to also enhance the self (Stets and Burke, 2000). The importance of attending to the needs of those within close social networks was paramount in the study participants' explanations for why they prioritize caring activities relating to these individuals over more formal forms of volunteering. This prioritization was sometimes manifest in adverse psychological outcomes that were endured for the sake of the welfare of in-group care recipients. Similarly, participants reported being prepared to forsake other activities to ensure they were available at the times they were needed and to juggle multiple forms of caring to cater to the concurrent needs of multiple in-group members (temporal factors). The tendency for females to be over-represented in the sub-sample relative to the overall sample is consistent with previous research indicating that caring is a 
largely gendered pastime, with females being more likely than males to perceive a need to undertake caring roles (Horrell et al., 2015).

Social capital theory, which originated in sociology, has similarities to social identity theory in that it relates to the way in which individuals structure themselves into networks that facilitate cooperation to produce mutually beneficial outcomes (Putnam, 1995). The emphasis is on the benefits that accrue to the individual from the number and type of connections held with others in their environment, and how these connections constitute a form of investment that can be called upon when needed (Portes, 1998). The study participants' prioritization of the needs of those in their immediate social networks, and especially members of their vertical family structures, may reflect the honoring of obligations to the elder generation and an investment in the wellbeing of younger generations who could subsequently become a source of future care and assistance for the individual. The scale of this social investment was once again apparent in the psychological and temporal issues that were regularly overcome to provide the required levels of care.

The finding that high levels of social capital may encourage informal volunteering and caring at the expense of formal volunteering contrasts with previous work that has conceptualized social capital as a key determinant of formal volunteering (Brown and Ferris 2007; Wilson and Musick, 1997). For study participants with very strong social ties, it seemed that these close connections may effectively constitute obligations to enact caring roles if and when the need arises, resulting in a prioritization of informal caring roles. As such, it seems that social capital may be an important element of the decision to undertake both formal and informal caring roles. An implication of this observation is that functional accounts of volunteering motivations that focus on how the outcomes of volunteering can enhance the well-being of 
the individual providing the service (Bales, 1996; Clary and Snyder, 1999; Clary et al., 1998) may also apply to caring roles.

Crossing both social psychology and sociology, role theory refers to the predictability of people's actions resulting from their own expectations of their roles relative to the roles of those around them (Biddle, 1986). Previous work has highlighted the function of role identity in determining whether individuals engage in informal caring duties (Finkelstein and Brannick, 2007). Role identity was especially evident in the present study in the case of child minding and eldercare, where many of the participants saw their contributions as being a more or less automatic aspect of their social role as grandparent or child, respectively. This outcome reflects the perceived obligatory nature of many informal volunteering and caring roles that makes their enactment an assumed aspect of individuals' lives (Hank and Stuck, 2008; Morgan et al., 2016).

The concept of psychological resilience refers to individuals' ability to cope with adverse circumstances and regain their equilibrium once the negative event has passed or reduced in intensity (Block and Kremen, 1996; Tugade et al., 2004). This concept was relevant to the psychological barriers discussed by those study participants who felt fully drained by the emotional burden of their caring duties. Some reported ongoing coping difficulties that prevented them from being able to contemplate future engagement in formal volunteering. Finally, anticipated regret theory, derived from the discipline of economics (Zeelenberg, 1999), appears applicable to the reluctance of some participants to take on additional responsibilities resulting from the fear of disappointing out-group members due to the prioritization of in-group members' needs. 


\section{Intervention implications}

The classification of barriers to formal volunteering into social, psychological, and temporal categories and the identification of relevant theoretical constructs for each category provides insights into the ways policies and programs can be developed or modified to better cater to the volunteering situations of older people. In the first instance, the clear importance of the needs of in-groups in determining whether the older person has the capacity to engage in formal volunteering highlights the substantial contributions seniors can make within their social networks - contributions that have value in their own right (Kelemen et al., 2017; Martinez et al., 2011). Childcare and eldercare were the most commonly reported informal roles reported by the study participants; these activities assist society as a whole by facilitating parents' return to work and enabling elderly relatives to age in place rather than being institutionalized.

These results indicate that programs designed to encourage formal volunteering among seniors therefore need to be implemented in a manner that recognizes that many potential volunteers will have other responsibilities that limit their ability to participate at any given time point, especially among those who are assisting in the care of multiple generations. Understanding and valuing these other contributions can prevent recruitment efforts from constituting an additional source of stress for those who may be already experiencing negative outcomes resulting from the emotional labor of their existing commitments. Such an approach is consistent with concerns about older people being placed under undue pressure to participate in formal volunteering and the noted importance of the power of 'invitation' (rather than coercion) and flexibility when providing seniors with volunteering opportunities (Morrow-Howell et al., 2017; Tang, Morrow-Howell, and Choi, 2010; Wang et al., 2016). It 
is also consistent with the call to recognize the existence and legitimacy of the 'fourth sector' that comprises informal volunteering activities and represents an important adjunct to the 'third sector' of formal volunteering (Williams, 2002).

The present results further highlight the importance of ensuring older caregivers have access to appropriate support programs to preserve their own health (Gonzales et al., 2015). In particular, carers are likely to need support to cope with the psychological pressures associated with assisting the dying, especially where they are called upon to perform this role repeatedly for their aging relatives. This may be a progressively more common phenomenon due to the increasing vertical integration of families (Puur et al., 2011), which is likely to result in fewer caregivers being available to meet the needs of the elder generation. For their own welfare, as well as their ability to continue to contribute to their in-groups and society more generally, these individuals need access to resources that provide them with the coping skills required to complete and recover from their caring roles (Adelman et al., 2014). In addition, increasing prevalence of chronic illness with older age means that many older carers have their own health needs to look after as well as those for whom they provide care, which increases their vulnerability and their need for external assistance (Jowsey et al., 2015; Schmidt et al., 2016). Previous research suggests that carers may not be aware of the services available to them (Bigby and Ozanne, 2004), and access to informed advice and assistance in arranging respite care in particular can be highly valued (Hancock et al., 2007). The increasing proficiency of older generations with internet technology highlights the potential for assistance to be also provided in the form of online information and support services (Bergström and Hanson, 2017). 
Finally, older people with informal volunteering and caring roles may still be able to participate in formal volunteering if temporal barriers can be overcome. Providing seniors with flexible volunteering options that are not time-sensitive may give them the opportunity to participate without the stresses associated with juggling complicated schedules and potentially letting others down. Volunteering roles associated with environmental conservation, for example, may be considerably less affected by late-notice cancellations and irregular participation than roles involving the provision of care to vulnerable people.

\section{Conclusion}

Although some prior research has concluded that targeting informal volunteers is a costeffective strategy for recruiting formal volunteers (Lee and Brudney, 2012), the results of the present study indicate that there may exist a sizeable minority of informal volunteers who are already working to capacity through their other contributions and according to their particular life circumstances. Care needs to be taken to understand and appreciate these other commitments while ensuring opportunities and encouragement to volunteer are available if and when these individuals are willing and able to participate. The matrix of volunteering barriers and associated theoretical frameworks generated in the present study provides insights into the diverse issues that need to be considered when developing programs specifically designed to attract and retain older volunteers. Given the exploratory nature of the study and its confinement to a single country, larger-scale work in a range of cultural contexts is needed to assess the extent to which these tentative findings apply elsewhere. 


\section{References}

Adelman, R. D., Tmanova, L. L., Delgado, D., Dion, S., \& Lachs, M. S. (2014). Caregiver burden: A clinical review. Journal of the American Medical Association, 311(10), 1052-1060.

Anderson, N. D., Damianakis, T., Kroger, E., Wagner, L. M., Dawson, D. R., Binns, M. A., et al. (2014). The benefits associated with volunteering among seniors: A critical review and recommendations for future research. Psychological Bulletin, 140(6), $1505-1533$.

Australian Bureau of Statistics. (2011a). Gender Indicators, Australia. (Catalog no. 4125.0). Canberra: ABS.

Australian Bureau of Statistics. (2011b). SEIFA Census of Population and Housing: SocioEconomic Indexes for Areas (SEIFA), Australia, 2011. (Catalog no. 2033.0.55.001). Canberra: ABS.

Australian Bureau of Statistics. (2015). General Social Survey: Summary Results, Australia, 2014. (Catalog no. 4159.0). Canberra: ABS.

Australian Bureau of Statistics. (2017a). Australian Demographic Statistics. (Catalog no. 3101). Canberra: ABS.

Australian Bureau of Statistics. (2017b). Discussion Paper: Information Needs for Volunteering Data, April 2017. (Catalog no. 4159.0.55.004). Canberra: ABS.

Australian Government. (2009). Secure and Sustainable Pensions. Canberra: Commonwealth of Australia.

Bales, K. (1996). Measuring the propensity to volunteer. Social Policy and Administration, 30, 206-226. 
Beard, J. R., \& Bloom, D. E. (2015). Towards a comprehensive public health response to population ageing. The Lancet, 385(9968), 658-661.

Bergström, A. L., \& Hanson, E. (2017). An integrative review of information and communication technology based support interventions for carers of home dwelling older people. Technology and Disability, 29(1-2), 1-14.

Biddle, B. J. (1986). Recent developments in role theory. Annual Review of Sociology, 12(1), $67-92$.

Bigby, C., \& Ozanne, E. (2004). Comparison of specialist and mainstream programs for older carers of adults with intellectual disability: considerations for service development. Australian Social Work, 57(3), 273-287.

Binder, M., \& Freytag, A. (2013). Volunteering, subjective well-being and public policy. Journal of Economic Psychology, 34, 97-119.

Block, J., \& Kremen, A. M. (1996). IQ and ego-resiliency: Conceptual and empirical connections and separateness. Journal of Personality and Social Psychology, 70(2), 349-361.

Bradley, E. H., Curry, L. A., \& Devers, K. J. (2007). Qualitative data analysis for health services research: Developing taxonomy, themes, and theory. Health Services Research, 42(4), 1758-1772.

Brown, K. M., Hoye, R., \& Nicholson, M. (2012). Self-esteem, self-efficacy, and social connectedness as mediators of the relationship between volunteering and well-being. Journal of Social Service Research, 38(4), 468-483.

Brown, E., \& Ferris, J. M. (2007). Social capital and philanthropy: An analysis of the impact of social capital on individual giving and volunteering. Nonprofit and Voluntary Sector Quarterly, 36(1), 85-99. 
Bulanda, J. R., \& Jendrek, M. P. (2016). Grandparenting Roles and Volunteer Activity. The Journals Of Gerontology. Series B, Psychological Sciences And Social Sciences, 71(1), 129-140.

Burr, J. A., Han, S. H., \& Tavares, J. L. (2015). Volunteering and cardiovascular disease risk: Does helping others get “under the skin?”. The Gerontologist, 56(5), 937-947.

Caro, F. G., \& Bass, S. A. (1997). Receptivity to volunteering in the immediate postretirement period. Journal of Applied Gerontology, 16(4), 427-441.

Carson, E. D. (1999). On defining the measuring volunteering in the United States and abroad. Law and Contemporary Problems, 62, 67.

Clary, E. G., \& Snyder, M. (1999). The motivation to volunteer: Theoretical and practical considerations. Current Directions in Psychological Science, 8(5), 156 - 159.

Clary, E. G., Snyder, M., Ridge, R. D., Copeland, J., Stukas, A. A., Haugen, J., \& Meine, P. (1998). Understanding and assessing the motivations of volunteers: A functional approach. Journal of Personality and Social Psychology, 74, 1516-1530.

Cnaan, R. A., \& Amrofell, L. (1994). Mapping volunteer activity. Nonprofit and Voluntary Sector Quarterly, 23(4), 335-351.

Connolly, S., \& O'shea, E. (2015). The perceived benefits of participating in voluntary activities among older people: Do they differ by volunteer characteristics? Activities, Adaptation \& Aging, 39(2), 95-108.

Creaven, A. M., Healy, A., \& Howard, S. (2017). Social connectedness and depression: Is there added value in volunteering? Journal of Social and Personal Relationships, 0265407517716786.

Dury, S., De Donder, L., De Witte, N., Brosens, D., Smetcoren, A. S., Van Regenmortel, S., \& Verte, D. (2016). Is volunteering in later life impeded or stimulated by other activities? Research on Aging, 38(1), 51-75. 
Finkelstein, M. A., \& Brannick, M. T. (2007). Applying theories of institutional helping to informal volunteering: Motives, role identity, and prosocial personality. Social Behavior and Personality, 35(1), 101-114.

Fram, S. M. (2013). The constant comparative analysis method outside of grounded theory. The Qualitative Report, 18(1), 1-25.

Gil-Lacruz, A. I., Marcuello, C., \& Saz-Gil, I. (2017). Individual and Social Factors in Volunteering Participation Rates in Europe. Cross-Cultural Research, 51(5) 464-490.

Glaser, B., \& Strauss, A. (1967). Discovering grounded theory. Chicago, IL: Aldine Publishing Company.

Gonzales, E., Matz-Costa, C., \& Morrow-Howell, N. (2015). Increasing opportunities for the productive engagement of older adults: A response to population aging. Gerontologist, 55(2), 252-261.

Gordon, R. L. (1969). Interviewing: Strategy techniques and tactics. Homewood, Ill: Dorsey Press.

Gray, E., Khoo, S.-E., \& Reimondos, A. (2012). Participation in different types of volunteering at young, middle and older adulthood. Journal of Population Research, 29(4), 373-398.

Grundy, E., \& Henretta, J. C. (2006). Between elderly parents and adult children: A new look at the intergenerational care provided by the 'sandwich generation'. Ageing \& Society, 26(5), 707-722.

Gupta, S. (2018). Impact of volunteering on cognitive decline of the elderly. The Journal of the Economics of Ageing, 12, 46-60.

Hancock, P. J., Jarvis, J. A., \& L'Veena, T. (2007). Older carers in ageing societies: An evaluation of a respite care program for older carers in Western Australia. Home Health Care Services Quarterly, 26(2), 59-84. 
Hank, K., \& Stuck, S. (2008). Volunteer work, informal help, and care among the 50+ in Europe: Further evidence for 'linked' productive activities at older ages. Social Science Research, 37(4), 1280-1291.

Ho, H. C. (2017). Elderly volunteering and psychological well-being. International Social Work, 60(4), 1028-1038.

Hong, S. I., \& Morrow-Howell, N. (2013). Increasing Older Adults' Benefits from Institutional Capacity of Volunteer Programs. Social Work Research, 37(2), 99-108.

Horrell, B., Stephens, C., \& Breheny, M. (2015). Capability to care: Supporting the health of informal caregivers for older people. Health Psychology, 34(4), 339.

Horsfall, D., Leonard, R., Rosenberg, J., \& Noonan, K. (2017). Home as a place of caring and wellbeing? A qualitative study of informal carers and caring networks lived experiences of providing in-home end-of-life care. Health and Place, 46, 58-64. doi:10.1016/j.healthplace.2017.04.003.

Horsfall, D., Noonan, K., \& Leonard, R. (2012). Bringing our dying home: How caring for someone at end of life builds social capital and develops compassionate communities. Health Sociology Review, 21(4), 373-382.

Hustinx, L., Cnaan, R. A., \& Handy, F. (2010). Navigating theories of volunteering: A hybrid map for a complex phenomenon. Journal for the Theory of Social Behaviour, 40(4), $410-434$

International Labour Office. (2011). Manual on the Measurement of Volunteer Work. Geneva, Switzerland.

Jowsey, T., McRae, I., Gillespie, J., Banfield, M., \& Yen, L. (2013). Time to care? Health of informal older carers and time spent on health related activities: an Australian survey. BMC Public Health, 13(1), 374. 
Kail, B. L., \& Carr, D. C. (2017). Successful aging in the context of the disablement process: Working and volunteering as moderators on the association between chronic conditions and subsequent functional limitations. The Journals of Gerontology: Series $B, 72(2), 340-350$.

Kahana, E., Bhatta, T., Lovegreen, L. D., Kahana, B., \& Midlarsky, E. (2013). Altruism, helping, and volunteering: pathways to well-being in late life. Journal of Aging and Health, 25(1), 159-187.

Kelemen, M., Mangan, A., \& Moffat, S. (2017). More than a 'little act of kindness'? Towards a typology of volunteering as unpaid work. Sociology, 51(6), 1239-1256.

Kim, E. S., \& Konrath, S. H. (2016). Volunteering is prospectively associated with health care use among older adults. Social Science \& Medicine, 149, 122-129.

Larkin, E., Sadler, S. E., \& Mahler, J. (2005). Benefits of volunteering for older adults mentoring at-risk youth. Journal of Gerontological Social Work, 44(3-4), 23-37.

Lee, Y., and Brudney, J. L. (2009). Rational volunteering: A benefit-cost approach. International Journal of Sociology and Social Policy, 29(9/10), 512-530.

Lee, Y., \& Brudney, J. L. (2012). Participation in formal and informal volunteering: Implications for volunteer recruitment. Nonprofit Management and Leadership, 23(2), 159-180.

Li, Y. P., Chen, Y. M., \& Chen, C. H. (2013). Volunteer transitions and physical and psychological health among older adults in Taiwan. Journals of Gerontology Series B: Psychological Sciences and Social Sciences, 68(6), 997-1008.

Li, Y., \& Ferraro, K. F. (2005). Volunteering and depression in later life: Social benefit or selection processes? Journal of Health and Social Behavior, 46(1), 68-84.

Lum, T. Y., \& Lightfoot, E. (2005). The effects of volunteering on the physical and mental health of older people. Research on Aging, 27(1), 31-55. 
Martinez, I. L., Crooks, D., Kim, K. S., \& Tanner, E. (2011). Invisible civic engagement among older adults: Valuing the contributions of informal volunteering. Journal of Cross-Cultural Gerontology, 26(1), 23-37.

Mitani, H. (2013). Influences of resources and subjective dispositions on formal and informal volunteering. VOLUNTAS: International Journal of Voluntary and Nonprofit Organizations, 25(4), 1022-1040.

Morgan, T., Ann Williams, L., Trussardi, G., \& Gott, M. (2016). Gender and family caregiving at the end-of-life in the context of old age: A systematic review. Palliative Medicine, 30(7), 616-624.

Morrow-Howell, N. (2010). Volunteering in later life: Research frontiers. The Journals of Gerontology: Series B, 65(4), 461-469.

Morrow-Howell, N., Gonzales, E. G., Harootyan, R. A., Lee, Y., \& Lindberg, B. W. (2017). Approaches, policies, and practices to support the productive engagement of older adults. Journal of Gerontological Social Work, 60(3), 193-200.

Petriwskyj, A. M., \& Warburton, J. (2007a). Motivations and barriers to volunteering by seniors: A critical review of the literature. The International Journal of Volunteer Administration, 24(6), 3-25.

Petriwskyj, A. M., \& Warburton, J. (2007b). Redefining volunteering for the global context: A measurement matrix for researchers. Australian Journal on Volunteering, 12(1), 713.

Plagnol, A. C., \& Huppert, F. A. (2009). Happy to help? Exploring the factors associated with variations in rates of volunteering across europe. Social Indicators Research, 97(2), 157-176.

Portes, A. (1998). Social capital: Its origins and applications in modern sociology. Annual Review of Sociology, 24(1), 1-24. 
Proulx, C. M., Curl, A. L., \& Ermer, A. E. (2017). Longitudinal associations between formal volunteering and cognitive functioning. The Journals of Gerontology: Series B, 73(3), $522-531$.

Putnam, R. D. (1995). Bowling alone: America's declining social capital. Journal of Democracy, 6(1), 65-78.

Puur, A., Sakkeus, L., Põldma, A., \& Herm, A. (2011). Intergenerational family constellations in contemporary Europe: Evidence from the Generations and Gender Survey. Demographic Research, 25, 135.

Schmidt, A. E., Ilinca, S., Schulmann, K., Rodrigues, R., Principi, A., Barbabella, F., ... \& Galenkamp, H. (2016). Fit for caring: factors associated with informal care provision by older caregivers with and without multimorbidity. European Journal of Ageing, 13(2), 103-113.

Smith, B., \& McGannon, K. R. (2017). Developing rigor in qualitative research: problems and opportunities within sport and exercise psychology. International Review of Sport and Exercise Psychology, doi.org/10.1080/1750984X.2017.1317357.

Stets, J. E., \& Burke, P. J. (2000). Identity theory and social identity theory. Social Psychology Quarterly, 63(3), 224-237.

Sundeen, R. A., Raskoff, S. A., \& Garcia, M. C. (2007). Differences in perceived barriers to volunteering to formal organizations: Lack of time versus lack of interest. Nonprofit Management and Leadership, 17(3), 279-300.

Tang, F., Choi, E., \& Morrow-Howell, N. (2010). Organizational support and volunteering benefits for older adults. Gerontologist, 50(5), 603-612.

Tang, F., Morrow-Howell, N., \& Choi, E. (2010). Why do older adult volunteers stop volunteering? Ageing \& Society, 30(5), 859-878. 
Taniguchi, H. (2011). The determinants of formal and informal volunteering: Evidence from the american time use survey. VOLUNTAS: International Journal of Voluntary and Nonprofit Organizations, 23(4), 920-939.

Tomioka, K., Kurumatani, N., \& Hosoi, H. (2017). Association between the frequency and autonomy of social participation and self-rated health. Geriatrics \& Gerontology International, 17(12), 2537-2544.

Tugade, M. M., Fredrickson, B. L., \& Feldman Barrett, L. (2004). Psychological resilience and positive emotional granularity: Examining the benefits of positive emotions on coping and health. Journal of Personality, 72(6), 1161-1190.

UK Cabinet Office. (2015). Community Life Survey: 2014-2015 Statistical Bulletin. https://www.gov.uk/government/uploads/system/uploads/attachment_data/file/447010 /Community_Life_Survey_2014-15_Bulletin.pdf.

US Bureau of Labor Statistics. (2016). Volunteering in the United States, 2015. https://www.bls.gov/news.release/volun.nr0.htm.

van der Horst, M., Vickerstaff, S., Lain, D., Clark, C., \& Baumberg Geiger, B. (2016). Pathways of paid work, care provision, and volunteering in later careers: Activity substitution or extension? Work, Aging and Retirement, 3(4), 343-365.

Wang, L., Mook, L., \& Handy, F. (2016). An empirical examination of formal and informal volunteering in canada. VOLUNTAS: International Journal of Voluntary and Nonprofit Organizations, 28(1), 139-161.

Warburton, J. (2015). The cultural dimensions of volunteering. In J. Twigg and W. Martin (Eds.), Handbook of Cultural Gerontology, Routledge, 345-352.

Warburton, J., \& Stirling, C. (2007). Factors affecting volunteering among older rural and city dwelling adults in australia. Educational Gerontology, 33(1), 23-43. 
Williams, C. C. (2002). Harnessing voluntary work: A fourth sector approach. Policy studies, 23(3), 247-260.

Wilson, J., \& Musick, M. (1997). Who cares? Toward an integrated theory of volunteer work. American Sociological Review, 62(5), 694-713.

Yeung, J. W. K. (2016). Religious involvement and participation in volunteering: Types, domains and aggregate. VOLUNTAS: International Journal of Voluntary and Nonprofit Organizations, 28(1), 110-138.

Zeelenberg, M. (1999). Anticipated regret, expected feedback and behavioral decision making. Journal of Behavioral Decision Making, 12(2), 93-106. 
Table 1: Sample Profile

\begin{tabular}{|c|c|c|}
\hline & $\begin{array}{c}\text { Total sample } \\
(\mathrm{n}=242) \\
\%\end{array}$ & $\begin{array}{c}\text { Informal } \\
\text { volunteering/caring } \\
\text { subsample } \\
(\mathrm{n}=49) \\
\% \\
\end{array}$ \\
\hline \multicolumn{3}{|l|}{ Gender } \\
\hline Male & 49 & 37 \\
\hline Female & 51 & 63 \\
\hline \multicolumn{3}{|l|}{ Age } \\
\hline $60-69$ & 51 & 59 \\
\hline $70-79$ & 42 & 38 \\
\hline $80+$ & 7 & 2 \\
\hline $\mathrm{M}(\mathrm{SD})$ & $69.91(5.96)$ & $68.12(4.71)$ \\
\hline \multicolumn{3}{|l|}{ Socioeconomic status ${ }^{a}$} \\
\hline Low & 10 & 16 \\
\hline Mid & 44 & 49 \\
\hline High & 46 & 35 \\
\hline \multicolumn{3}{|l|}{ Education } \\
\hline School & 3 & 39 \\
\hline Technical/trade certificate & 43 & 33 \\
\hline University & 47 & 29 \\
\hline Missing & $<1$ & 0 \\
\hline \multicolumn{3}{|l|}{ Living status } \\
\hline Live alone & 30 & 31 \\
\hline Live with someone & 70 & 69 \\
\hline
\end{tabular}

${ }^{\text {a }}$ Socioeconomic status derived from residential postcode as per the Australian Bureau of Statistics' Socio-Economic Indexes for Areas (SEIFA) classification (Australian Bureau of Statistics, 2011b). 
Table 2: Matrix of barrier categories and relevant theoretical frameworks

\begin{tabular}{|c|c|c|c|c|c|}
\hline \multirow[t]{2}{*}{ Barrier category } & \multicolumn{5}{|c|}{ Theoretical frameworks } \\
\hline & $\begin{array}{c}\text { Social } \\
\text { identity }\end{array}$ & Social capital & Roles & Resilience & $\begin{array}{c}\text { Anticipated } \\
\text { regret }\end{array}$ \\
\hline Social & $\mathrm{X}$ & $\mathrm{X}$ & $X$ & & \\
\hline Psychological & $\mathrm{X}$ & $\mathrm{X}$ & & $X$ & $X$ \\
\hline Temporal & $\mathrm{X}$ & $X$ & $\mathrm{X}$ & & \\
\hline
\end{tabular}

